\section{Effects of Insecticides on Gas Exchange, Vegetative and Floral Development, and Overall Quality of Gerbera}

\author{
James D. Spiers, Fred T. Davies, Jr., and Chuanjiu He \\ Department of Horticultural Sciences, Texas A\&M University, College Station, \\ TX 77843-2133
}

\author{
Carlos E. Bográn, Kevin M. Heinz \\ Department of Entomology, Texas A\&M University, College Station, \\ TX 77843-2150
}

Terri W. Starman
Department of Horticultural Sciences, Texas A\&M University, College Station,
TX 77843-2133

Amanda Chau

Department of Entomology, Texas A\&M University, College Station, TX 77843-2150

Additional index words. Gerbera jamesonii, acephate, bifenthrin, neem oil, spinosad, abamectin, photosynthesis, phytotoxicity, stomatal conductance, thrips

\begin{abstract}
This study evaluated the influence of insecticides on gas exchange, chlorophyll content, vegetative and floral development, and plant quality of gerbera (Gerbera jamesonii Bolus 'Festival Salmon'). Insecticides from five chemical classes were applied weekly at $1 \times$ or $4 \times$ their respective recommended concentration. The insecticides used were abamectin (Avid), acephate (Orthene), bifenthrin (Talstar), clarified hydrophobic extract of neem oil (Triact), and spinosad (Conserve). Photosynthesis and stomatal conductance were reduced in plants treated with neem oil. Plants treated with neem oil flowered later-and at $4 \times$ the recommended label concentration had reduced growth, based on lower vegetative dry mass (DM) and total aboveground DM, reduced leaf area, thicker leaves (lower specific leaf area), higher chlorophyll content (basal leaves), and reduced flower production. Plants treated with acephate at $4 \times$ the recommended label concentration were of the lowest quality due to extensive phytotoxicity (leaf chlorosis). Plants treated with $1 \times$ or $4 \times$ abamectin or spinosad were of the highest quality due to no phytotoxicity and no thrips damage (thrips naturally migrated into the greenhouse). The control plants and plants treated with $1 \times$ bifenthrin had reduced quality because of thrips feeding damage; however gas exchange was not negatively affected.
\end{abstract}

Gerbera (Gerbera jamesonii Bolus) is an economically important greenhouse crop produced and sold for cut flowers, potted plants, and bedding plants. Gerbera is highly susceptible to a variety of insect pests including aphids, spider mites, and its most important insect pest-western flower thrips [(WFT) Frankliniella occidentalis Pergande]. WFT are difficult to control due to their biology and feeding behavior (Robb, 1989). WFT prefer to feed within flowers and buds, which protect them from harmful insecticides and natural enemies. Hence, insecticides are often applied

\footnotetext{
Received for publication 22 Sept. 2005. Accepted for publication 20 Feb. 2006. We gratefully appreciate the technical assistance of Alejandro Alarcon and Leslie Scheuring. We thank Knox Nursery, Inc. for donation of gerberas. We also thank Olympic Horticultural Products, Syngenta, FMC Corporation, and Dow AgroSciences for donation of insecticides used in this study. We also greatly appreciate Yin Tung Wang for review of this paper. Financial support was provided in part by the USDA-National Research Initiative for Floriculture Research, grant \#58-6204-0.106, the American Floral Endowment, and Texas Agricultural Experiment Station.
}

at frequent intervals to prevent damage from occurring. However, WFT populations may rapidly develop resistance to insecticides when they are used on a continual basis (Immaraju et al., 1992; Jensen 2000).

Insecticides from various insecticide classes with diverse modes of action are frequently used on gerbera to control insect pests and reduce the risk of insecticide resistance. Due to increasing concerns over the use of conventional insecticides in greenhouse production, reduced-risk insecticides are used because they are less toxic to workers, have short residual properties, and minimal adverse environmental impact (Lowery and Isman, 1995; Miller and Uetz, 1998). These insecticides also may have a narrower spectrum of activity against pest species and may require frequent applications to achieve production goals. The continual presence of these insecticides on plant foliage may adversely affect plant growth processes. Insecticides are typically evaluated for visible phytotoxicity prior to their registration, but subtle impacts on plant physiology, growth, and development are not often tested.
Biorational insecticides are becoming increasingly popular in the management of greenhouse insect pests to minimize reliance on more toxic chemicals. "Biorational" refers to pesticides of natural origin that have limited or no effects on the environment or beneficial organisms. Miller and Uetz (1998) evaluated several biorational insecticides (horticultural oil, insecticidal soap, and neem extract) for phytotoxicity on a variety of greenhouse crops. No phytotoxicity was observed on flowers or foliage of bedding plants and plant height did not appear to be affected by the treatments. However, horticultural oil (SunSpray UF spray oil, Mycogen Corp., San Diego, Cal.) and insecticidal soap (M-Pede, Mycogen, Corp., San Diego, Cal.) caused leaf burn and reduced growth in potted poinsettia (Euphorbia pulcherrima Willd.); while neem extract (Azatin, AgriDyne, Salt Lake City, Utah) had no adverse affect (Miller and Uetz, 1998). Only obvious phytotoxic effects were evaluated, while plant gas exchange, biomass, and development were not measured. The effects of biorational insecticides on gerbera have not been reported.

Some insecticides have translaminaractivity, in which the material enters the leaf to form a reservoir of active ingredient. When these materials enter the leaf cuticle, they may impact plant gas exchange processes, and alter plant growth and development. Acephate, a commonly used organophosphate insecticide with translaminar activity, has been reported to be phytotoxic to greenhouse crops such as chrysanthemum(Dendranthema grandiflora Tzvelev 'Charm')(Spiers et al., 2004) and peace lily (Spathiphyllum Schott 'Clevelandii') (Chase and Poole, 1984). Organophosphate insecticides have also been reported to reduce photosynthesis in strawberries (LaPré et al., 1982), oranges (Jones et al., 1983), and lettuce (Haile et al., 2000). Studies on the effects of insecticides on gas exchange have been conducted primarily on agronomic crops with varying results (Abdel-Reheem et al., 1991; Godfrey and Holtzer, 1992; Veeraswamy et al., 1993). Many of these studies were conducted using insecticides that are no longer commercially available or are not registered for use on ornamental greenhouse crops. The effect of commonly used insecticides, as well as newly introduced compounds, needs to be addressed in determining how they affect plant gas exchange, and the subsequenteffects on plant development, quality, and production.

Pesticides have varying recommendations for application rates based on the crop, pest, and at times application methods. Method and number of applications as well as combination with non-pesticides occasionally influence photosynthesis (Ferree, 1979). Haile et al. (2000) reported that the surfactant (Kinetic; Helena Chem. Co., Memphis, Tenn.), alone reduced photosynthetic rates in seedling lettuce. Several pesticides, surfactants, or carriers are oil-based. Oil-based formulations may mechanically interfere with gas exchange by blocking plant stomates, thus reducing stomatal conductance and photosynthesis (Ferree, 1979).

While insecticides may adversely affect plants, few studies have reported insecticidal effects on host plant physiology in addition to 
plant growth and development. In this study, five insecticides that are commonly used in greenhouse crop production were chosen to represent various classes of insecticides: organophosphates, pyrethroids, spinosyn, macrocyclic lactone, and botanical. Each of the selected insecticides is used for thrips control in gerbera greenhouse production. The objective of this study was to determine the effects of selected insecticides, when applied $1 \times$ or $4 \times$ the recommended label concentration, on the physiology and growth of gerbera.

\section{Materials and Methods}

Plant cultural conditions. In total, 84 Gerbera jamesonii Bolus 'Festival Salmon' seedlings were transplanted into 6-inch standard pots $\left(15.5 \times 11.5 \mathrm{~cm} ; 2050 \mathrm{~cm}^{3}\right)$ on 11 June 2004. Each pot with one established seedling plug was a single replication. Sunshine Mix \#1 (Sun Gro Horticulture Inc., Pine Bluff, Ark.) was used as the growing media. Gerberas were grown according to recommended cultural practices for pot plant production (Benke, 1991; Kessler, 1999). Plants were initially placed pot-to-pot for $5 \mathrm{~d}$, then were evenly spaced (about $33 \times 33 \mathrm{~cm}$ apart) on two benches $(1.2$ $\mathrm{m} \times 3.7 \mathrm{~m})$. Plants were fertilized as needed with $150 \mathrm{mg} \cdot \mathrm{L}^{-1} \mathrm{~N}$ for 3 weeks, then with 250 $\mathrm{mg} \cdot \mathrm{L}^{-1} \mathrm{~N}$ for the remainder of the experiment. At each irrigation, plants were fertilized with a $15 \mathrm{~N}-7 \mathrm{P}-14 \mathrm{~K}$ fertilizer (Peters Professional Peat-lite special 15-16-17, Scotts-Sierra Horticultural Products Co., Marysville, Ohio). The greenhouse temperature and relative humidity (RH) was recorded hourly using data loggers (Watchdog Data Logger model 150; Spectrum Technologies, Inc., Plainfield, Ill.). Data loggers were placed at canopy level (about $20 \mathrm{~cm}$ high) in the center of each bench. The average day and night temperature were, respectively, 28.4 $\pm 0.1{ }^{\circ} \mathrm{C}$ and $23.5 \pm 0.2{ }^{\circ} \mathrm{C}$. The average day and night RH were, respectively, $74 \%$ and $91 \%$. A line quantum sensor was placed at canopy level in the center of each bench to determine photosynthetic photon flux (PPF). PPF was recorded hourly with an Apogee nanologger model MCQI (Apogee Instruments Inc., Logan, Utah). Daily peak light intensity averaged 421

Fig. 1. Effect of insecticides and concentration on (A) flower number; (B) days to flower, determined by number of days from transplanting to pollen shed of the most mature flower; and (C) overall plant quality. Gerberas were rated on a quality rating scale of 1 to 5 on day 57 , based on the following scale: 1 = extensive damage on leaves and/or flowers due to thrips feeding or phytotoxicity; 2 = excessive to moderate injury; including distorted flowers and/or leaves due to thrips feeding or phytotoxicity; $3=$ moderate injury from thrips feeding or phytotoxicity; $4=$ acceptable quality plant with slight thrips feeding damage or phytotoxicity; $5=$ high quality plant with healthy flowers and foliage, and no thrips feeding injury or phytotoxicity. Means were separated using Fisher's protected least significant difference (LSD) test $(P \leq 0.05)$; treatments followed by the same letter are not significantly different; $1 \times=$ recommended concentration, $4 \times=4$ times the recommended concentration; see Table 3. $\mu \mathrm{mol} \cdot \mathrm{m}^{-2} \cdot \mathrm{s}^{-1}$. There were no significant differences among benches.

Etridiazole/thiophanate-methyl [Banrot Broad Spectrum Fungicide 40\% WP (ScottsSierra Crop Protection Co., Marysville, Ohio)] was applied at a rate of $600 \mathrm{mg} \cdot \mathrm{L}^{-1}$ to all pots $4 \mathrm{~d}$ after planting. The plant growth regulator, daminozide, (B-Nine, UniroyalChemicalCompany Inc., Middlebury, Conn.) was sprayed on all plants at $2500 \mathrm{mg} \cdot \mathrm{L}^{-1}$ to the point of runoff, $19 \mathrm{~d}$ after transplanting to reduce leaf expansion and encourage compact growth. The experiment was terminated after $57 \mathrm{~d}$ on 6 Aug. 2004.

Insecticidal treatments. Treatments con- sisted of five insecticides and one control (control plants were sprayed with de-ionized water). Insecticides were applied weekly at $1 \times$ or $4 \times$ the recommended concentration. The $4 \times$ concentration was included to maximize the potential phytotoxic response. There were seven plants or replicates for each treatment. The recommended concentrations and rates varied for the selected insecticides. The recommended concentrations and rate (weekly) used in this study were based on insecticide label instructions for thrips control on greenhouse floral crops. The insecticides and recommended concentrations (in g a.i./100 L) were: acephate
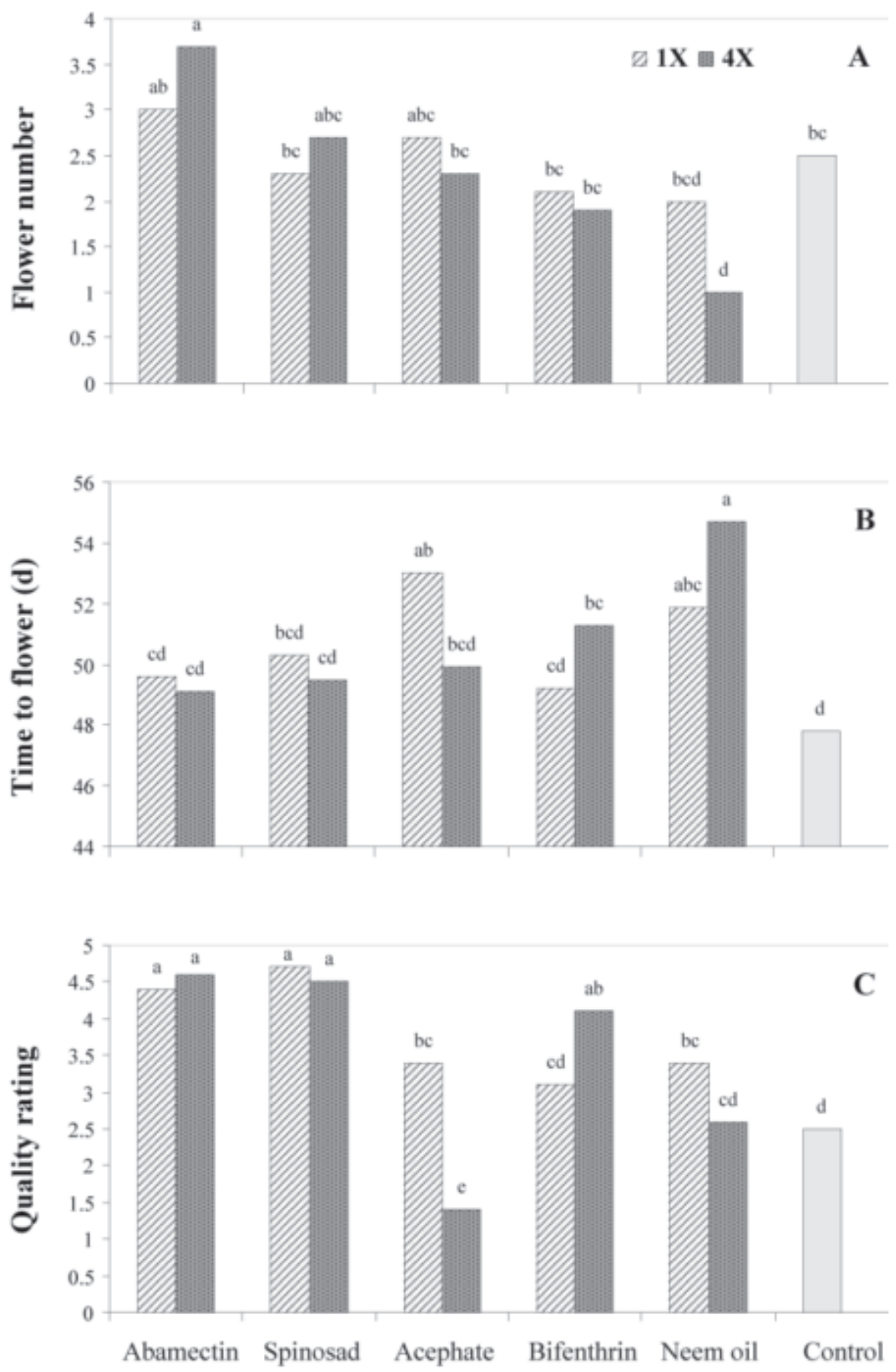

\section{Insecticide}


(Orthene 97; ValentU.S.A.Corp., WalnutCreek, Calif.), 58; bifenthrin (Talstar; FMC Corp., Philadelphia, Pa.), 27; spinosad (Conserve SC; Dow AgroSciences LLC, Indianapolis, Ind.), 21; clarified hydrophobic extract of neem oil (Triact 70; Olympic Horticultural Products Co., Mainland, Pa.), 654; and abamectin (Avid 0.15 EC; Syngenta Crop Protection Inc., Greensboro, N.C.), 1. Each plant was sprayed using a handheld 700-mL sprayer(Spraymaster; Delta Industries, King of Prussia, Pa.) until runoff (about $90 \mathrm{~mL}$ per plant). Spray applications started 6 $\mathrm{d}$ after transplanting and continued weekly for the duration of the experiment (total $=8$ applications). Insecticides were applied between the hours of 08:00 to 10:30 HR.

Plant growth measurements. Vegetative dry mass (DM), leaf area, specific leaf area (SLA, $\mathrm{cm}^{2} \cdot \mathrm{g}^{-1} \mathrm{DM}$ of leaves), and total aboveground plant DM were determined at the termination of the experiment (day 57) to characterize plant growth. Both vegetative and reproductive plant parts were included in the total aboveground DM measurements. Plants were cut at the soil line, dried at $70{ }^{\circ} \mathrm{C}$ for $96 \mathrm{~h}$, and weighed to determine DM.

Flower development. Flowernumber, flower $\mathrm{DM}$, and reproductive DM (flowers, flower buds, and peduncles) were determined at the termination of the experiment to assess the effect of the insecticide treatments on flower production. The rate of flower development was determined by recording the number of days from transplanting to pollen shed of the most mature flower.

Plant quality characteristics. Plant quality was determined by rating each plant (1 to 5 , with $5=$ optimal) (Fig. 1). The quality rating was based on overall aesthetic quality and was determined using the following scale: $1=\mathrm{ex}$ tensive damage on leaves and/or flowers due to thrips feeding or phytotoxicity; 2 = excessive to moderate injury; including distorted flowers and/ or leaves due to thrips feeding or phytotoxicity; 3 = moderate injury from thrips feeding damage or phytotoxicity; 4 = quality plant with slight thrips feeding damage or phytotoxicity; $5=$ high quality plant with no thrips feeding damage or phytotoxicity. Statistical significance for the quality ratings was determined with a two-way ANOVA design for ranked data - the ScheirerRay-Hare extension of the Kruskal-Wallis Test (Sokal and Rohlf, 1995).

Chlorophyll determination. Leafchlorophyll concentration was determined with a portable chlorophyll meter(SPAD-502; Minolta Camera Co., LTD, Japan). The SPAD-502 meter readings were correlated with a chlorophyll content prediction equation: $\mathrm{y}=1.4929 \mathrm{x}-12.979$, where $\mathrm{y}=$ chlorophyll content $\left(\mu \mathrm{g} \cdot \mathrm{cm}^{-2}\right), \mathrm{x}=$ meter reading $\left(R^{2}=0.9683\right)$. This equation was obtained by running a linear regression analysis between the SPAD-502 readings obtained in a separate fertility study with physiologically mature leaves from five pots per fertility treatment (six treatments); and the total chlorophyll concentration of the same leaves (J.D. Spiers, unpublished data). Leaf chlorophyll was extracted with N, N-dimethylformamide (DMF) and the total concentration was determined by the optical density of filtered aqueous superna- tant, which was measured at $647 \mathrm{~nm}$ and 664 nm with a spectrophotometer (Moran, 1982). Each leaf was a single replication and one physiologically mature leaf, and one older, basal leaf was randomly selected from each plant and measured at the end of the experiment with the SPAD-502 meter $(\mathrm{n}=7)$.

Plantgas exchange. Net photosynthesis $(P n)$ and stomatal conductance $\left(\mathrm{g}_{\mathrm{s}}\right)$ measurements of individual leaves were taken one day after each insecticide application between 11:00 and 15:30 HR using a portable photosynthesis system (LI-6400; LI-COR Inc., Lincoln, Neb.). A fixed substrate level of $360 \mu \mathrm{L} \cdot \mathrm{L}^{-1} \mathrm{CO}_{2}$ was provided with a 12-g cartridge, and the light source was a LED $6400 \mathrm{R} / \mathrm{B}$ at $600 \mu \mathrm{mol} \cdot \mathrm{m}^{-2} \cdot \mathrm{s}^{-1}$. Each leaf was a single replication, and there were 3 replications per treatment $(\mathrm{n}=3)$.

Experimental design and statistical data analysis. The experiment was arranged as a six $\times$ two factorial design. Each pot had one established seedling plug as a replicate. There were seven replications per treatment arranged and flowers), vegetative, and total aboveground dry mass (DM) of Gerbera jamesonii 'Festival Salmon'. Significance was determined with insecticide (I) and insecticide concentration (C) as main treatments.

\begin{tabular}{|c|c|c|c|c|c|}
\hline Insecticide & C & $\begin{array}{l}\text { Flower } \\
\text { DM } \\
\text { (g) }\end{array}$ & $\begin{array}{c}\text { Reproductive } \\
\text { DM } \\
\text { (g) }\end{array}$ & $\begin{array}{l}\text { Vegetative } \\
\text { DM } \\
\text { (g) }\end{array}$ & $\begin{array}{c}\text { Total } \\
\text { aboveground } \\
\text { DM } \\
\text { (g) }\end{array}$ \\
\hline \multirow{2}{*}{ Abamectin } & $1 \times$ & $1.3 \mathrm{abcd}^{2}$ & $2.2 \mathrm{abc}$ & $6.1 \mathrm{ab}$ & $8.3 \mathrm{ab}$ \\
\hline & $4 \times$ & $1.8 \mathrm{a}$ & $2.6 \mathrm{ab}$ & $6.0 \mathrm{ab}$ & $8.6 \mathrm{ab}$ \\
\hline \multirow[t]{2}{*}{ Spinosad } & $1 \times$ & $1.3 \mathrm{abcd}$ & $2.9 \mathrm{a}$ & $6.5 \mathrm{a}$ & $9.3 \mathrm{a}$ \\
\hline & $4 \times$ & $1.5 \mathrm{abc}$ & $2.6 \mathrm{ab}$ & $5.8 \mathrm{abc}$ & $8.4 \mathrm{ab}$ \\
\hline \multirow[t]{2}{*}{ Acephate } & $1 \times$ & $1.6 \mathrm{ab}$ & $2.6 \mathrm{ab}$ & $5.1 \mathrm{bc}$ & $7.7 \mathrm{bc}$ \\
\hline & $4 \times$ & $1.0 \mathrm{~cd}$ & $1.6 \mathrm{~cd}$ & $4.6 \mathrm{c}$ & $6.2 \mathrm{c}$ \\
\hline \multirow[t]{2}{*}{ Bifenthrin } & $1 \times$ & $1.2 \mathrm{bcd}$ & $2.0 \mathrm{bcd}$ & $6.4 \mathrm{a}$ & $8.4 \mathrm{ab}$ \\
\hline & $4 \times$ & $1.1 \mathrm{~cd}$ & $1.9 \mathrm{bcd}$ & $5.7 \mathrm{abc}$ & $7.6 \mathrm{bc}$ \\
\hline \multirow[t]{2}{*}{ Neem oil } & $1 \times$ & $0.9 \mathrm{~d}$ & $1.4 \mathrm{~d}$ & $4.8 \mathrm{c}$ & $6.2 \mathrm{c}$ \\
\hline & $4 \times$ & $0.4 \mathrm{e}$ & $0.7 \mathrm{e}$ & $3.3 \mathrm{~d}$ & $4.0 \mathrm{~d}$ \\
\hline \multicolumn{5}{|l|}{ Significance } & $7.5 \mathrm{bc}$ \\
\hline I & & 0.0005 & $<0.0001$ & $<0.0001$ & $<0.0001$ \\
\hline $\mathrm{C}$ & & NS & 0.0451 & 0.0213 & 0.0046 \\
\hline $\mathrm{I} \times \mathrm{C}$ & & 0.0002 & $<0.0001$ & 0.0001 & $<0.0001$ \\
\hline
\end{tabular}

${ }^{2}$ Treatments followed by the same letter are not significantly different. Means were separated using Fisher's protected least significant difference (LSD) test $P \leq 0.05$.

${ }^{\text {NS}}$ Nonsignificant; $\mathrm{n}=7$.

Table 2. Effect of insecticide treatments on leaf area, specific leaf area (SLA), and chlorophyll content of physiologically mature (PM) and basal leaves of Gerbera jamesonii 'Festival Salmon'. Significance is determined with insecticide (I) and insecticide concentration (C) as main treatments.

\begin{tabular}{|c|c|c|c|c|c|}
\hline Insecticide & C & $\begin{array}{l}\text { Leaf } \\
\text { area } \\
\left(\mathrm{cm}^{2}\right)\end{array}$ & $\begin{array}{c}\text { SLA } \\
\left(\mathrm{cm}^{2} \cdot \mathrm{g}^{-1}\right)\end{array}$ & $\begin{array}{c}\text { Chlorophyll } \\
(\mathrm{PM} \text { leaf) } \\
\left(\mu \mathrm{g} \cdot \mathrm{cm}^{-2}\right)\end{array}$ & $\begin{array}{c}\text { Chlorophyll } \\
\text { (basal leaf) } \\
\left(\mu \mathrm{g} \cdot \mathrm{cm}^{-2}\right)\end{array}$ \\
\hline \multirow[t]{2}{*}{ Abamectin } & $1 \times$ & $1345 a b^{z}$ & $225 \mathrm{a}$ & $69.2 \mathrm{bcd}$ & $69.2 \mathrm{bcd}$ \\
\hline & $4 \times$ & $1318 \mathrm{ab}$ & $221 \mathrm{ab}$ & $72.7 \mathrm{abc}$ & $68.1 \mathrm{~cd}$ \\
\hline \multirow[t]{2}{*}{ Spinosad } & $1 \times$ & $1441 \mathrm{a}$ & $222 \mathrm{ab}$ & $69.4 \mathrm{bcd}$ & $66.1 \mathrm{~d}$ \\
\hline & $4 \times$ & $1219 a b c$ & $210 \mathrm{abcd}$ & $68.3 \mathrm{~cd}$ & $67.7 \mathrm{~cd}$ \\
\hline \multirow[t]{2}{*}{ Acephate } & $1 \times$ & 1099 bc & $220 a b c$ & $67.5 \mathrm{~d}$ & $68.1 \mathrm{~cd}$ \\
\hline & $4 \times$ & $966 \mathrm{c}$ & 209 abcd & $69.2 \mathrm{bcd}$ & $73.4 \mathrm{ab}$ \\
\hline \multirow[t]{2}{*}{ Bifenthrin } & $1 \times$ & $1322 \mathrm{ab}$ & $208 \mathrm{abcd}$ & $70.9 \mathrm{abcd}$ & $68.1 \mathrm{~cd}$ \\
\hline & $4 \times$ & $1131 \mathrm{bc}$ & $201 \mathrm{~cd}$ & $69.6 \mathrm{bcd}$ & $72.5 \mathrm{abc}$ \\
\hline \multirow[t]{2}{*}{ Neem oil } & $1 \times$ & $980 \mathrm{c}$ & $207 \mathrm{abcd}$ & $74.5 \mathrm{a}$ & $73.4 \mathrm{ab}$ \\
\hline & $4 \times$ & $651 \mathrm{~d}$ & $193 \mathrm{~d}$ & $73.8 \mathrm{ab}$ & $75.4 \mathrm{a}$ \\
\hline \multicolumn{6}{|l|}{ Significance } \\
\hline I & & $<0.0001$ & 0.0060 & 0.0201 & 0.0029 \\
\hline $\mathrm{C}$ & & 0.0032 & 0.0292 & NS & 0.0392 \\
\hline $\mathrm{I} \times \mathrm{C}$ & & $<0.0001$ & 0.0459 & 0.0928 & 0.0051 \\
\hline
\end{tabular}

${ }^{2}$ Treatments followed by the same letter are not significantly different. Means were separated using Fisher's protected least significant difference (LSD) test, $P \leq 0.05$.

${ }^{\text {NSNonsignificant } ;} \mathrm{n}=7$. 
and $4 \times$ bifenthrin treated plants compared to plants treated with $1 \times$ spinosad-which had the greatest total aboveground DM (Table 1). The $1 \times$ spinosad treated plants also had greater leaf area than the control plants (Table 2). Plants treated with $4 \times$ acephate had reduced vegetative $\mathrm{DM}$ and total aboveground $\mathrm{DM}$ due to phytotoxicity (leaf burn) (Table 1). Plants treated with $4 \times$ acephate or neem oil had among the lowest leaf areas, with $4 \times$ neem oil treated plants also having the lowest specific leaf area (SLA) [thickest leaves].

Flower development. Flower production was negatively affected by neem oil or acephate applied at $4 \times$ the recommended concentrations. Plants treated with $4 \times$ neem oil had reduced flower and reproductive DM (Table 1), and fewer flowers when compared to control plants (Fig. 1A, Table 3). The $4 \times$ acephate plants had reduced flower and reproductive DM compared to plants treated with the $1 \times$ acephate concentration (Table 1). The control and bifenthrin treated plants had reduced flower DM and reproductive $\mathrm{DM}$, primarily due to thrips feeding damage (Table 1). Plants treated with abamectin, spinosad, or $1 \times$ acephate had the greatest flower production. Neem oil, $1 \times$ acephate, and $4 \times$ bifenthrin treated plants flowered later than control plants (Fig. 1B; Table 3).

Plant quality. Plants treated with abamectin and spinosad at $1 \times$ or $4 \times$ the recommended concentration were of the highest quality due to no phytotoxicity or thrips feeding damage (Fig. $1 \mathrm{C}$, Table 3$)$. The $4 \times$ acephate treated plants were rated as the lowest quality plants due to severe phytotoxicity. Plants treated with neem oil had reduced quality due to excessively stunted growth and reduced flower quality. Control and $1 \times$ bifenthrin plants were of low quality due to thrips feeding damage.

Leaf chlorophyll. Leaf chlorophyll content tended to be greater in physiologically mature leaves of plants treated with neem oil, though not significant when compared to control plants (Table 2). Plants treated with $4 \times$ acephate had increased chlorophyll content in older, basal leaves; though the edges of the basal leaves were necrotic due to phytotoxicity. The plants treated with $4 \times$ neem oil had greater chlorophyll levels in basal leaves (Table 2).

Plant gas exchange. Gas exchange data from four dates are presented in Figs. 2 and 3. Leaf photosynthesis $(P n)$ and stomatal conductance $(g)$ were reduced in plants treated with $1 \times$ or $4 \times$ neem oil, with the $4 \times$ treated plants having the lowest gas exchange. While the $4 \times$ acephate treatment was severely phytotoxic to basal leaves, net $P n$ and $g$ sere not reduced in the physiologically mature leaves when compared to the control plants. Thrips infestation did not appear to affect gas exchange in control

Fig. 2. Effect of insecticides and concentration on net photosynthesis $(P n)$ of physiologically mature leaves; $\mathrm{n}=3$. Data for Day 7 was not significantly different. Means were separated using Fisher's protected least significant difference (LSD) test $(P \leq 0.05)$; treatments followed by the same letter are not significantly different; $1 \times=$ recommended concentration, $4 \times=4$ times the recommended concentration; see Table 4.

Table 3. ANOVA P values of flower development and overall quality of gerbera insecticide study with insecticide (I) and insecticide concentration (C) as main treatments.

\begin{tabular}{lcccccc}
\hline Flower no. & & \multicolumn{2}{c}{ Days to flower } & & \multicolumn{2}{c}{ Quality rating } \\
\cline { 3 - 4 } Source & $P$ & Source & & & Source & $P$ \\
\hline $\mathrm{I}$ & 0.001 & $\mathrm{I}$ & 0.0031 & & $\mathrm{I}$ & $<0.0001$ \\
$\mathrm{C}$ & $\mathrm{NS}$ & $\mathrm{C}$ & $\mathrm{NS}$ & & $\mathrm{C}$ & $\mathrm{NS}$ \\
$\mathrm{I} \times \mathrm{C}$ & 0.0036 & $\mathrm{I} \times \mathrm{C}$ & 0.0032 & & $\mathrm{I} \times \mathrm{C}$ & $<0.0001$ \\
\hline
\end{tabular}

${ }^{\text {NSNonsignificant; }} \mathrm{n}=7$.

and bifenthrin treated plants. There were no statistical differences in gas exchange the day after the first application of insecticides (Figs. 2A and 3A, Table 4). $P n$ increased as plants matured and remained consistent after 2 weeks of growth (Fig. 2).

\section{Discussion}

We report on the effects of insecticides from five chemical classes on gas exchange, plant growth and development, chlorophyll content,
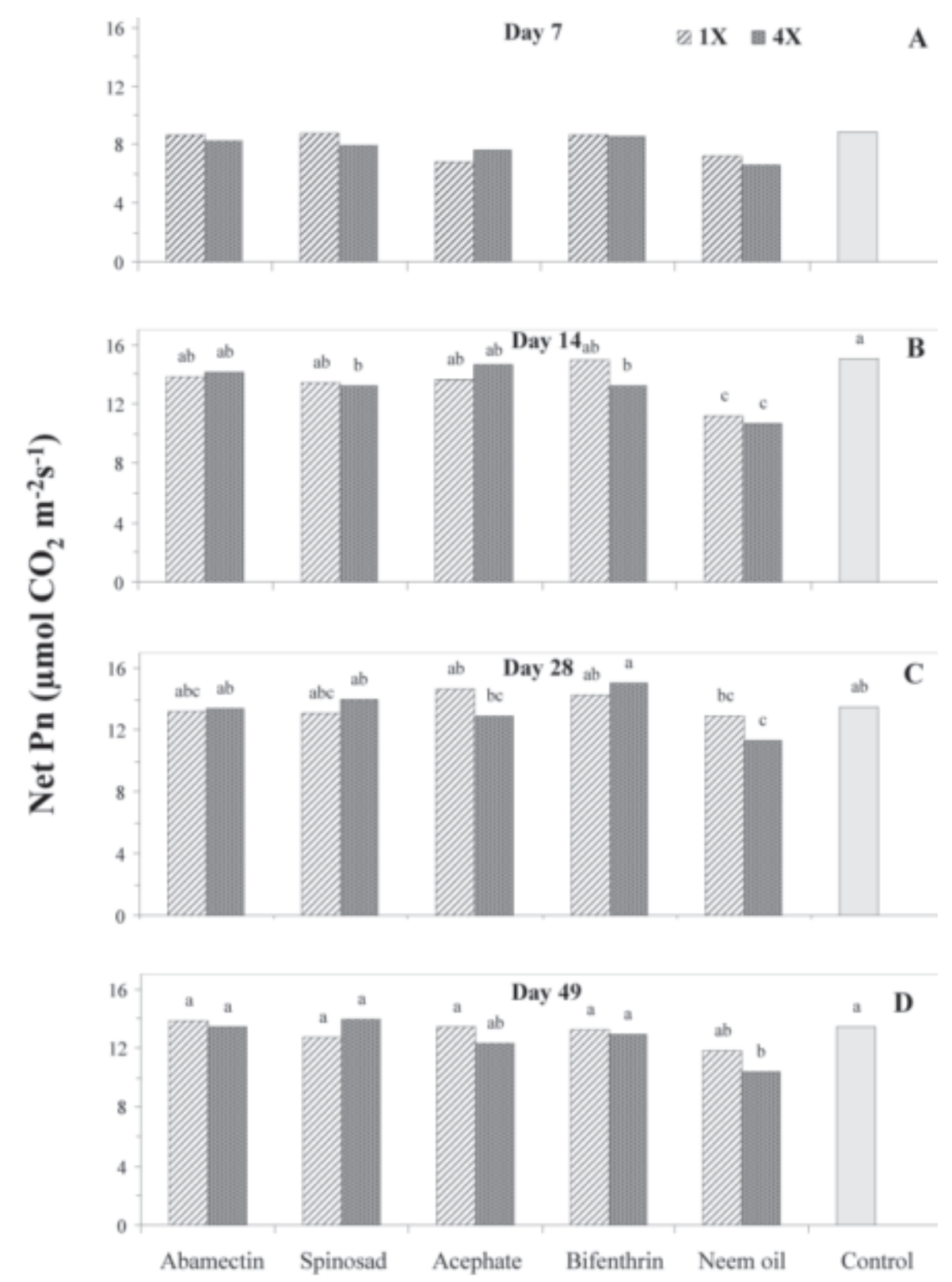

Insecticide 

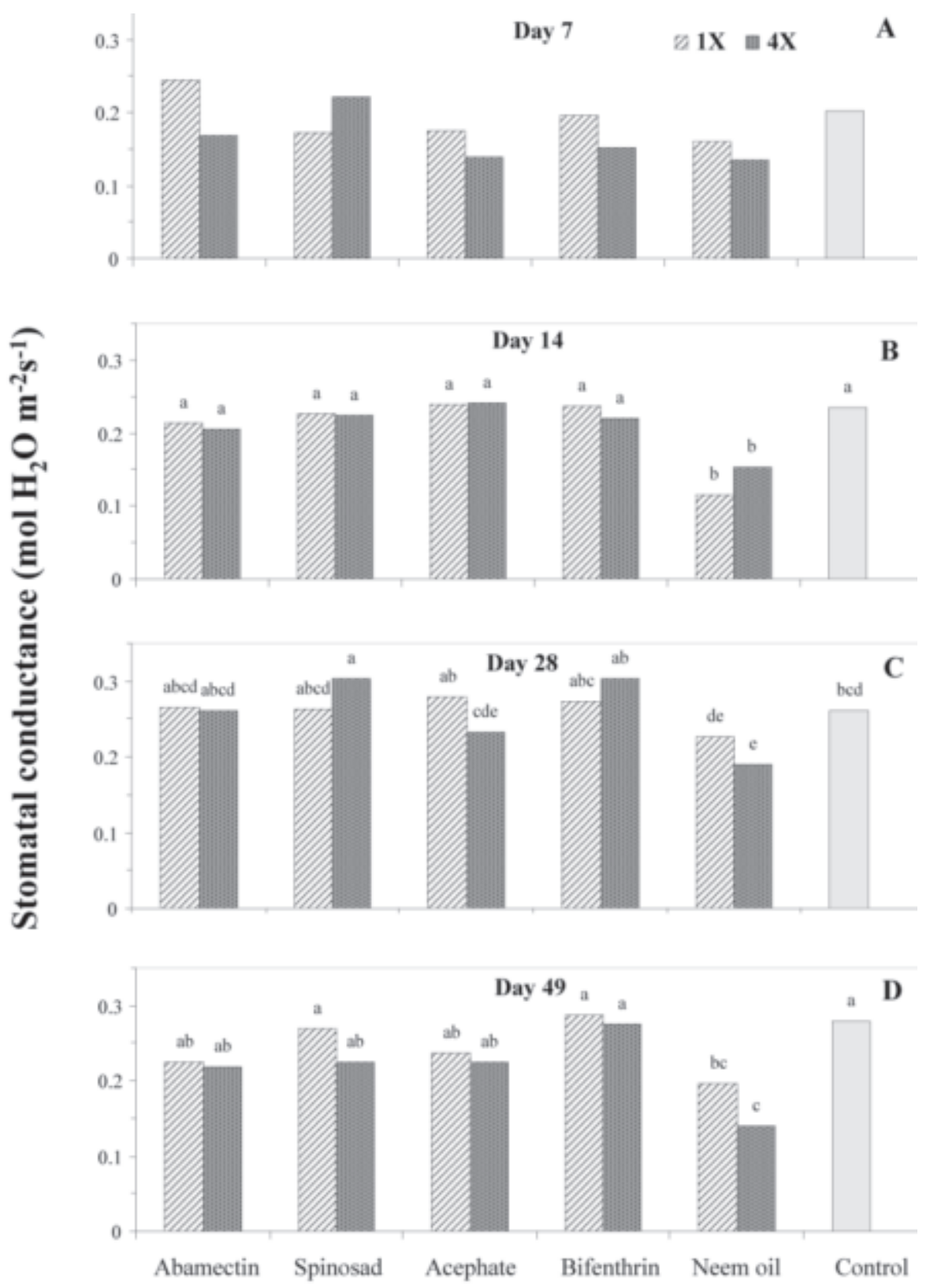

Insecticide

Table 4. ANOVA values for gas exchange parameters of gerbera insecticide study with insecticide (I) and insecticide concentration (C) as main treatments.

\begin{tabular}{|c|c|c|c|c|}
\hline & \multicolumn{2}{|c|}{ Net photosynthesis $(P n)$} & \multicolumn{2}{|c|}{ Stomatal conductance $\left(g_{s}\right)$} \\
\hline & Source & $\mathrm{P}$ & Source & $\mathrm{P}$ \\
\hline \multicolumn{5}{|l|}{ Day 7} \\
\hline & I & NS & I & NS \\
\hline & $\mathrm{C}$ & NS & $\mathrm{C}$ & NS \\
\hline & $\mathrm{I} \times \mathrm{C}$ & NS & $\mathrm{I} \times \mathrm{C}$ & NS \\
\hline \multicolumn{5}{|l|}{ Day 14} \\
\hline & I & $<0.0001$ & I & $<0.0001$ \\
\hline & $\mathrm{C}$ & NS & $\mathrm{C}$ & NS \\
\hline & $\mathrm{I} \times \mathrm{C}$ & $<0.0001$ & $\mathrm{I} \times \mathrm{C}$ & $<0.0001$ \\
\hline \multicolumn{5}{|l|}{ Day 28} \\
\hline & I & 0.0391 & I & 0.0021 \\
\hline & $\mathrm{C}$ & NS & $\mathrm{C}$ & NS \\
\hline & $\mathrm{I} \times \mathrm{C}$ & 0.0493 & $\mathrm{I} \times \mathrm{C}$ & 0.001 \\
\hline \multicolumn{5}{|l|}{ Day 49} \\
\hline & I & 0.0342 & I & 0.0009 \\
\hline & $\mathrm{C}$ & NS & $\mathrm{C}$ & NS \\
\hline & $\mathrm{I} \times \mathrm{C}$ & NS & $\mathrm{I} \times \mathrm{C}$ & 0.0116 \\
\hline
\end{tabular}

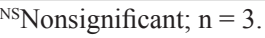

Fig. 3. Effect of insecticides and concentration on stomatal conductance $\left(g_{s}\right)$ of physiologically mature leaves; $n=3$. Data for Day 7 was not significantly different. Means were separated using Fisher's protected least significant difference (LSD) test $(P \leq 0.05)$; treatments followed by the same letter are not significantly different; $1 \times=$ recommended concentration, $4 \times=4$ times the recommended concentration; see Table 4.

1982). As SLAdecreases, leafconstruction costs increase-which typically reduces leafnitrogen, stomatal conductance, and photosynthesis rates (Poorter and Evans 1998).

Plants treated with $4 \times$ acephate were rated as the lowest quality plants due to severe phytotoxicity, i.e., leaf burn, which contributed to reduced vegetative and total aboveground DM (Table 1), and reduced leaf area (Table 2). The highest quality plants were those treated with $1 \times$ or $4 \times$ spinosad or abamectin. These plants experienced no adverse effects from insecticidal applications or the natural infestation of thrips that damaged the control and bifenthrin treated plants.

Due to the natural infestation of thrips, the control plants and bifenthrin treated plants had substantial thrips feeding damage. Bifenthrin (Talstar) is labeled for thrips control; however, thrips control was not achieved by weekly bifenthrin applications in this study. Based on visual inspection, thrips feeding damage became noticeable at approximately week 7 of the experiment, when flower buds were present. It is possible that small thrips populations were maintained on bifenthrin treated plants because insecticide applications did not come into direct contact with thrips. Bifenthrin (Talstar) is a contact insecticide, thus thrips must be contacted directly to be affected. The thrips may have avoided contact with insecticide treatments by feeding within flower buds and flowers (Robb, 1989). Thrips are also capable of developing resistance to bifenthrin. Field populations of western flower thrips [Frankliniella occidentalis (Pergande)] showed high levels of resistance to bifenthrin (Talstar 10WP; FMC Corp., Princeton, N.J.) in laboratory experiments conducted by Immaraju et al. (1992).

Davies et al. (2005) reported that western flower thrips feeding damage reduced plant biomass, stomatal conductance, and photosynthesis in chrysanthemum (Dendranthema grandiflora Tzvelev 'Charm'). In our study, thrips feeding did not appear to affect host plant physiology (Figs. 2 and 3, Table 4), in part because thrips infestation occurred during later stages of production. Control and $4 \times$ bifenthrin plants did havereduced total aboveground DM when compared to plants treated with $1 \times$ spinosad (Table 1). However, plants treated with $4 \times$ bifenthrin had less noticeable thrips feeding damage on flowers and were rated higher than control and $1 \times$ bifenthrin treated plants (Fig. 1C). None of the other treatments exhibited noticeable thrips feeding damage.

Neem oil, which can be used as a fungicide and an insecticide in potted gerbera production, had a growth retarding effect in this study. It is a common practice to apply a growth retardant in potted gerbera production to manage excessive flower scape elongation and leaf expan- 
sion. Some plant growth retardants control the crop's growth by influencing the plant's phytohormones, such as blocking gibberellic acid biosynthesis. However, the plants treated with neem oil had reduced plant growth and development due to reduced net photosynthesis and stomatal conductance (Figs. 2 and 3, Table 4). Plants treated with neem oil also had reduced quality due to excessively stunted growth and reduced flower quality. Open flowers treated with neem oil were brownish and flagging due to the weight of the oil solution. However, when used sparingly on vegetation, neem oil may prove to be useful for managing leaf expansion in gerbera, in addition to providing insect and pathogen control.

Insecticides and surfactants with an oilbased formulation are more likely to interfere with plant gas exchange compared with other formulations (Ferree, 1979). Youngman et al. (1990) determined that reduced photosynthesis was partly attributed to reduced mesophyll conductance. In our study, both stomatal conductance and photosynthesis were reduced by neem oil. Insecticides that reduce plant gas exchange generally do so only transiently, lasting for a few days (Ferree, 1979; Haile et al., 2000; LaPré et al., 1982). Weekly applications of neem oil caused a reduction in gas exchange for the duration of the study; however, the $1 \times$ neem oil plants seemed to recover photosynthetic capacity toward the end of the study (Figs. 2 and 3, Table 4). It should be noted that gas exchange was measured $1 \mathrm{~d}$ after insecticide treatments, and photosynthesis rates may have increased in succeeding days. Abamectin (Avid 0.15 EC) was applied as an emulsifiable concentrate, but the emulsifier did not affect gas exchange in this experiment. This could be attributed to the low volume that is permitted for use in greenhouse production. The recommended concentration for thrips suppression is $0.6 \mathrm{~mL} \cdot \mathrm{L}^{-1}$ for abamectin (Avid $0.15 \mathrm{EC}$ ) compared to $10 \mathrm{~mL} \cdot \mathrm{L}^{-1}$ for neem oil (Triact 70).

Severe effects such as phytotoxicity can be minimized by restrictions on application timing, method, or rate, as instructed on the pesticide label. Increases in either fertilizer level or temperature resulted in increased levels of phytotoxicity when Spathiphyllum plants were sprayed with recommended rates of acephate (Chase and Poole, 1984). In our study, insecticides were applied in early morning to minimize temperature effects. The broad spectrum fungicide, Banrot - which was applied in this experiment, did not cause any phytotoxicity nor affect gas exchange in a preliminary study (J.D. Spiers, unpublished data).

In summary, abamectin, spinosad, and bifenthrin did not alter plant gas exchange, and did not negatively affect plant growth and development - even when applied at $4 \times$ the recommended concentration. Abamectin has been reported to be phytotoxic to ferns (Green et al., 1985) and pear (Hilton et al., 1992), but appears to be safe for use on most ornamentals (Green et al., 1985). Acephate, when applied according to label instructions, does not affect plant growth and development or plant gas exchange on gerbera. However, acephate can be phytotoxic to gerbera when applied at concentrations above label recommendations, as demonstrated in our experiment. Neem oil reduced plant gas exchange, plant growth and development, and flower production; with greatest reductions occurring at $4 \times$ the label concentration.

The insecticides were chosen to represent different chemical classes with the assumption that the active ingredients would differentially affect plant growth and development. While this was true for acephate, which was phytotoxic at $4 \times$ the recommended label concentration, most of the insecticides used in this experiment did not adversely affect gas exchange or growth and development — even when applied at supraoptimal levels. However, spray oils that have the potential to mechanically interfere with gas exchange are the most likely to reduce photosynthesis. With the exception of oil-based formulations, it is unlikely that insecticides currently registered for use on ornamental greenhouse crops are phytotoxic, or affect gas exchange or plant growth and development, when used according to label recommendations.

\section{Literature Cited}

Abdel-Reheem, S., M.H. Belal, and G. Gupta. 1991. Photosynthesis inhibition of soybean leaves by insecticides. Environ. Pollut. 74:245-250.

Benke, M. 1991. Gerbera (Transvaal daisy), p. 555-558. In: V. Ball (ed.). Ball redbook -greenhouse growing. 15th ed. Geo J. Ball, Inc., West Chicago, Ill.

Chase,A.R. and R.T. Poole. 1984. Severity of acephate phytotoxicity on Spathiphyllum Schott. cv. Clevelandii as influenced by host nutrition and temperature. J. Amer. Soc. Hort. Sci. 109:168-172.

Davies, Jr., F.T., C. He, A. Chau, J.D. Spiers, and K.M. Heinz. 2005. Fertiliser application affects susceptibility of chrysanthemum to western flower thrips-abundance and influence on plant growth, photosynthesis and stomatal conductance. J. Hort. Sci. Biotechnol. 80:403-412.

Ferree, D.C. 1979. Influence of pesticides on photosynthesis of crop plants, p. 331-341. In: R. Marcelle, H.C. Clijsters, and M. Van Poucke (eds.). Photosynthesis and plant development. Junk, The Hague.

Godfrey, L.D. and T.O. Holtzer. 1992. Effects of soil-incorporated insecticides and foliar-applied chemicals on corn gas-exchange parameters. Crop Protection 11:427-432.

Green,A.St.J., B. Heijne, J. Schreurs, and R.A. Dybas. 1985. Serpentine leafminer (Liriomyza trifolii) (Burgess) control with abamectin (MK-936) in Dutch ornamentals. A review of the processes involved in the evolution of the use directions, and a summary of the results of phytotoxic evaluations. Intl. Symp. Crop Protection 37:603-622.
Haile, F.J., D.L. Kerns, J.M. Richardson, and L.G. Higley. 2000. Impact of insecticides and surfactant on lettuce physiology and yield. J. Econ. Entomol. 93:788-793.

Hilton, R.J., H. Riedl, and P.H. Westigard. 1992. Phytotoxicity response of pear to application of abamectin-oil combinations. HortScience 27:1280-1282.

Hoelmer, K.A., L.S. Osborne, and R.K. Yokomi. 1990. Effects of neem extracts on beneficial insects in greenhouse culture. In: J.C. Locke and R.H. Lawson (eds.). Neem's potential in pest management programs. Proc. USDA Neem Wkshp. 86:100-105.

Hunt, R. and P.S. Lloyd. 1987. Growth and partitioning. New Phytol. 106:235-249.

Immaraju, J.A., T.D. Paine, J.A. Bethke, K.L. Robb, and J.P. Newman. 1992. Western flower thrips (Thysanoptera: Thripidae) resistance to insecticides in coastal Californian greenhouses. J. Econ. Entomol. 85:9-14.

Jensen, S.E. 2000. Insecticide resistance in the western flower thrips, Frankliniella occidentalis. Integr. Pest Mgt. Rev. 5:131-146.

Jones, V.P., R.R. Youngman, and M.P. Parrella. 1983. Effect of selected acaricides on photosynthesis rates of lemon and orange leaves in California. J. Econ. Entomol. 76:1390-1394.

Kessler, Jr., J.R. 1999. Greenhouse production of gerbera daisies. ACES Publ., ANR-1144.

LaPré, L.F., F.V. Sances, N.C. Toscano, E.R. Oatman, V. Voth, and M.W. Johnson. 1982. The effect of acaricides on the physiology, growth, and yield of strawberries. J. Econ. Entomol. 75:616-619.

Lowery, D.T. and M.B. Isman. 1995. Toxicity of neem to natural enemies of aphids. Phytoparasitica 23:297-306.

Miller, F. and S. Uetz. 1998. Evaluating biorational pesticides for controlling arthropod pests and their phytotoxic effects on greenhouse crops. HortTechnology 8:185-192.

Moran, R. 1982. Formulae for determination of chlorophyllous pigments extracted from N,N-dimethylformamide. Plant Physiol. 69:1376-1381.

Poorter, H. and J.R. Evans. 1998. Photosynthetic nitrogen-use efficiency of species that differ inherently in specific leaf area. Oecologia 116:26-37.

Robb, K.L. 1989. Analysis of Frankliniella occidentalis Pergande as a pest of floriculture crops in California greenhouses. PhD diss. Univ. Calif., Riverside.

SAS Institute Inc. 2000. SAS/Stats user's guide, version 8. SAS Inst. Inc., Cary, N.C.

Sokal, R.R. and F.J. Rohlf. 1995. Assumptions of analysis of variance, p. 423-447. In: Biometry. 3rd ed. W.H. Freeman and Company, New York.

Spiers, J.D., F.T. Davies, C. He, A. Chau, K.M. Heinz, and T.W. Starman. 2004. Effect of insecticides from five chemical classes on the growth and production of pot mums (Dendranthema grandiflora Tzvelev var. Charm). Proc. S. Nur. Assn. Res. Conf. 49:168-172.

Veeraswamy,J., T. Padmavathi, and K. Venkateswarlu. 1993. Effect of selected insecticides on plant growth and mycorrhizal development in sorghum. Agr. Ecosyst. Environ. 43:337-343.

Youngman, R.R., T.F. Leigh, T.A. Kerby, N.C. Toscano, and C.E. Jackson. 1990. Pesticides and cotton: effect on photosynthesis, growth, and fruiting. J. Econ. Entomol. 83:1549-1557. 